\title{
RESEARCH REPORT \\ THE NEED AND MEANS TO UPDATE CHRONOLOGIES IN A DYNAMIC ENVIRONMENT
}

\section{EVAN R. LARSON*, SARA ALLEN, NICHOLAS L. FLINNER, STEVEN G. LABARGE, and THOMAS C. WILDING}

Tree-Ring, Earth, and Environmental Sciences Laboratory, Department of Social Sciences, University of WisconsinPlatteville, Platteville, WI 53818, USA

\begin{abstract}
The International Tree-Ring Data Bank (ITRDB) provides public access to over 3000 tree-ring data sets collected over the past century, yet 809 of these sites have end dates between AD 1950 and 1980. These data cannot be calibrated with at least the past 30-40 years of instrumental data when used in climate reconstructions. We developed new tree-ring data sets at five sites in Maine, USA, to update earlier collections. Four of the five collections were successfully updated, with environmental changes at the fifth site limiting our success. Our results highlight the limits to tree longevity in a dynamic world and the need to increase and formalize efforts toward updating chronologies. We initiate a discussion to set forth explicit guidelines that help create consistent efforts to updating chronologies and provide a guide to beginning dendrochronologists who are particularly well suited to contribute to this area of work. The research was carried out through an introductory dendrochronology course taught at the University of Wisconsin-Platteville and offers a model to help direct the increasing availability of human resources to the rapidly growing field of dendrochronology.
\end{abstract}

Keywords: dendrochronology, chronology length, Picea, Tsuga, Pinus, Maine.

\section{INTRODUCTION}

Dendrochronology has grown tremendously as a science over the past century, both in terms of methodological sophistication and the geographic coverage of tree-ring data. Spurred by rapid growth in the discipline, the number of sites with available tree-ring data began to increase at an accelerating pace in the 1970s and early 1980s. The International Tree-Ring Data Bank (ITRDB) reflects this development with the most recent year of 809 tree-ring data sets falling between AD 1950 and 1980, with another 856 sites ending in the 1980s (Figure 1) (Grissino-Mayer and Fritts 1997). The ring-width data from many of these sites cannot be calibrated with instrumental climate data over at least the last 30 years, a period that includes potentially unprecedented activity with respect to trend, variability, and extreme events in the climate system (IPCC 2007),

\footnotetext{
*Corresponding author: larsonev@uwplatt.edu; Fax (608) 342-1088; Telephone: (608) 342-6139
}

as well as a divergence between climate and tree growth at some sites (D'Arrigo et al. 2008). The value of previously developed chronologies can be enhanced through new collections that update the available data and enable their calibration with the full instrumental record, thus giving a more complete understanding of climate-tree growth relationships and past climate variability.

The objective of this research was to update several chronologies developed in Maine, USA. The project was conducted in the context of an introductory dendrochronology course at the University of Wisconsin-Platteville during the spring 2010 semester. The course was designed to expose undergraduate students to the basic principles of dendrochronology, gain hands-on experience analyzing tree rings and ring-width data from a variety of species, and report their work through presentations and a publication. Field and laboratory efforts were coupled with student-led discussions of Hal Fritts' Tree Rings and Climate (1976) that helped students under- 


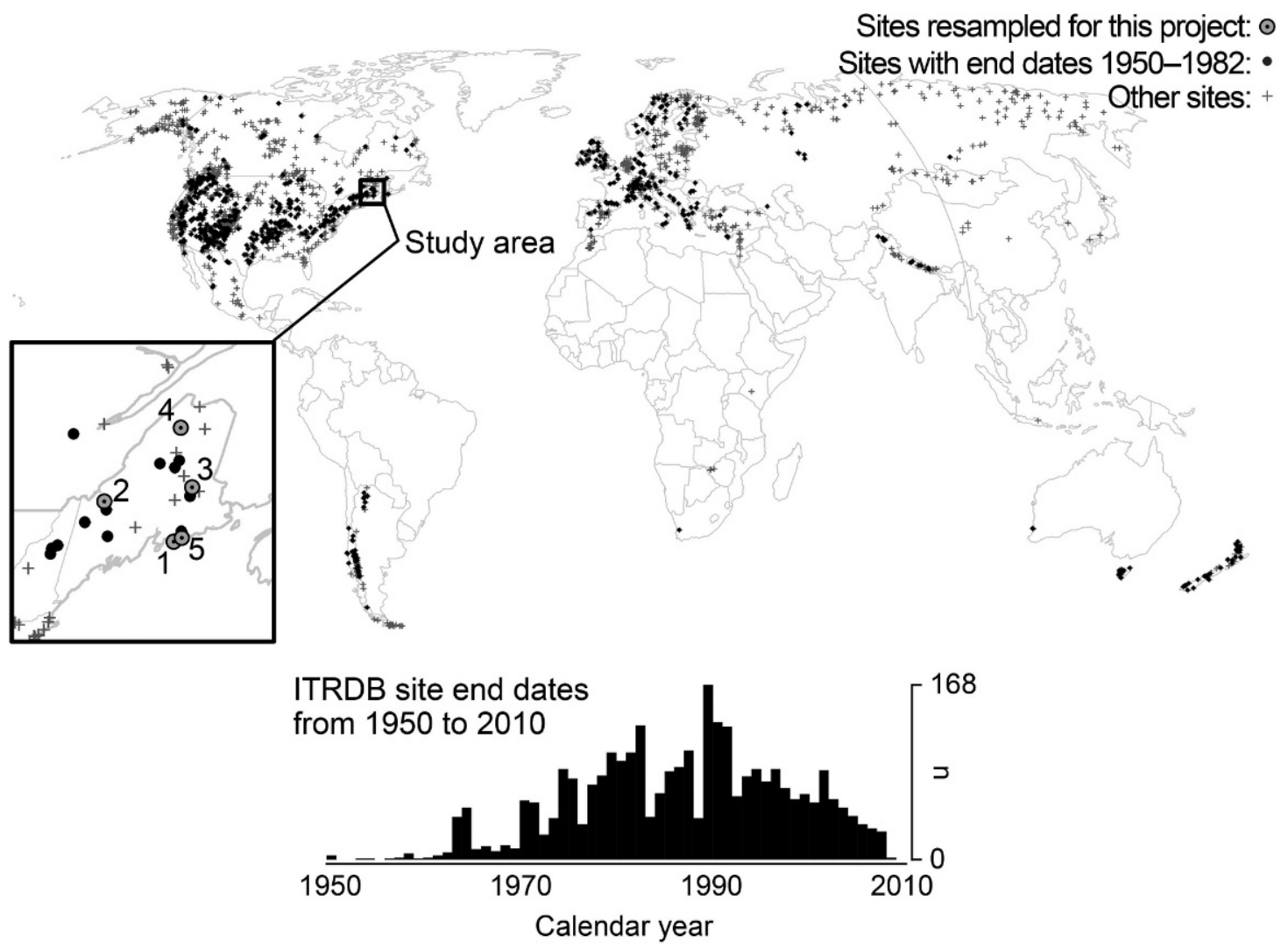

Figure 1. Sites with tree-ring data available through the International Tree-Ring Data Bank (ITRDB) and the distribution of chronology end dates from 1950 to 2010. Site numbers correspond to Table 1 and Figure 2.

stand some of the practical and theoretical underpinnings of tree-ring research.

\section{METHODOLOGY AND RESULTS}

The locations of all tree-ring collection sites in Maine on the ITRDB were obtained and ranked in order of preference based on our ability to relocate the previous sampling locations, the species and end dates of the previously collected chronologies, and our ability to gain sampling permission. In all, five sites were sampled during the summer of 2009 (Figure 1, Table 1). Increment cores were collected along at least two radii from 9-20 living trees at each site. Trees were selected based on visual appearance of old age to overlap as much as possible with the existing chronologies.

The samples were prepared and analyzed by teams of two students. All of the samples were air dried, glued into wooden core trays, and hand sanded up to ANSI 400-grit (20.6-23.6 $\mu \mathrm{m})$ sandpaper (Orvis and Grissino-Mayer 2002). Students crossdated each sample using marker rings identified in the newly collected cores through skeleton plotting and visual inspection of the cores (Stokes and Smiley 1996). Once master plots and lists were developed for each site they were compared to the COFECHA outputs of the previously collected chronologies to determine their accuracy (Holmes 1983; Grissino-Mayer 2001). All dates were checked by the student teams and the course instructor. Ring widths were either measured using a Velmex system interfaced with Measure J2X or scanned and measured in WinDENDRO v. 9c. Assessment of crossdating and measurement accuracy using the computer program COFECHA (Holmes 1983; GrissinoMayer 2001) indicated that the student teams 
Table 1. Comparisons between previously-collected and newly-developed tree-ring data at five sites in Maine, USA, including Pearson's $r$, paired Student's T-tests, and F-tests (* indicates a significant value at $\mathrm{p}<0.05)$. Site numbers correspond to location numbers in Figure 1 and Figure 2.

\begin{tabular}{|c|c|c|c|c|c|c|c|}
\hline Site & Years & $\begin{array}{c}\text { Mean interseries } \\
\text { correlation }\end{array}$ & $\begin{array}{c}\text { Mean } \\
\text { sensitivity }\end{array}$ & $\begin{array}{l}\text { Mean segment } \\
\text { length }\end{array}$ & $r$ & $t$ & $f$ \\
\hline \multicolumn{8}{|c|}{ 1. Acadia National Park (Pinus strobus) } \\
\hline Previous collection & $1840-1992$ & 0.524 & 0.22 & 61 & $0.68^{*}$ & 0.30 & 1.20 \\
\hline Update & $1824-2009$ & 0.519 & 0.22 & 147 & & & \\
\hline \multicolumn{8}{|c|}{ 2. Cathedral Pines (Pinus resinosa) } \\
\hline Previous collection & $1795-1973$ & 0.558 & 0.21 & 173 & $0.81^{*}$ & 0.17 & 1.15 \\
\hline Update & $1792-2009$ & 0.567 & 0.20 & 202 & & & \\
\hline \multicolumn{8}{|c|}{ 3. Matawaumkeag (Tsuga canadensis) } \\
\hline Previous collection & $1697-1981$ & 0.645 & 0.25 & 259 & $0.86^{*}$ & 0.18 & 1.06 \\
\hline Update & $1721-2009$ & 0.583 & 0.26 & 195 & & & \\
\hline \multicolumn{8}{|c|}{ 4. Sag Pond (Thuja occidentalis) } \\
\hline Previous collection & $1674-1986$ & 0.535 & 0.21 & 246 & $0.40^{*}$ & $3.91 *$ & $0.66^{*}$ \\
\hline New collection & $1777-2009$ & 0.458 & 0.20 & 124 & & & \\
\hline \multicolumn{8}{|c|}{ 5. Ironbound Island (Picea rubens) } \\
\hline Previous collection & $1665-1982$ & 0.469 & 0.24 & 233 & $0.73 *$ & 0.22 & 0.96 \\
\hline Update & $1830-2009$ & 0.481 & 0.18 & 144 & & & \\
\hline
\end{tabular}

produced well-dated, high-quality tree-ring data (Table 1).

We developed standardized ring-width index (RWI) chronologies from the previously and newly collected tree-ring data for each site using interactive detrending in the computer program ARSTAN version 41d (Cook and Krusic 2005). Students were required to identify and justify appropriate curve fits for each measurement series based on their own interpretations of the raw ringwidth data (sensu Fritts 1976). This proved to be an effective approach to illustrating the critical step of standardization in the development of RWI chronologies.

The RWI chronologies developed by the student teams from the previously collected data and the newly collected samples showed strong graphical similarities in most cases, with the exception of those for Sag Pond (Figure 2). The new chronologies were significantly correlated with the original chronologies in all cases, though the correlation between the Sag Pond chronologies was weaker (Table 1). The newly developed chronologies at Acadia National Park and Cathedral Pines extended further into the past than the previously collected chronologies. We were unable to find trees of equal age to those sampled at the other three sites. Mean interseries correlations, calculated as the mean of all correlations between each individual series and a master dating series derived from the other samples at each site (Holmes 1999), were similar between the chronologies at each site except Matawaumkeag and Sag Pond where the newly developed chronologies showed lower correlations. Paired Student's t-tests and F-tests indicated no difference in means or variances between the chronologies except those from Sag Pond. Given the standardization methods applied, the significant differences observed between the chronologies from Sag Pond indicate that the signals expressed therein are fundamentally different from each other. The newly developed tree-ring data provide reasonable updates to all sites except Sag Pond, which should instead be considered a new collection.

\section{DISCUSSION}

\section{Updating Chronologies as a Teaching Opportunity}

The process of updating a tree-ring chronology can be relatively simple and hardly justifies 


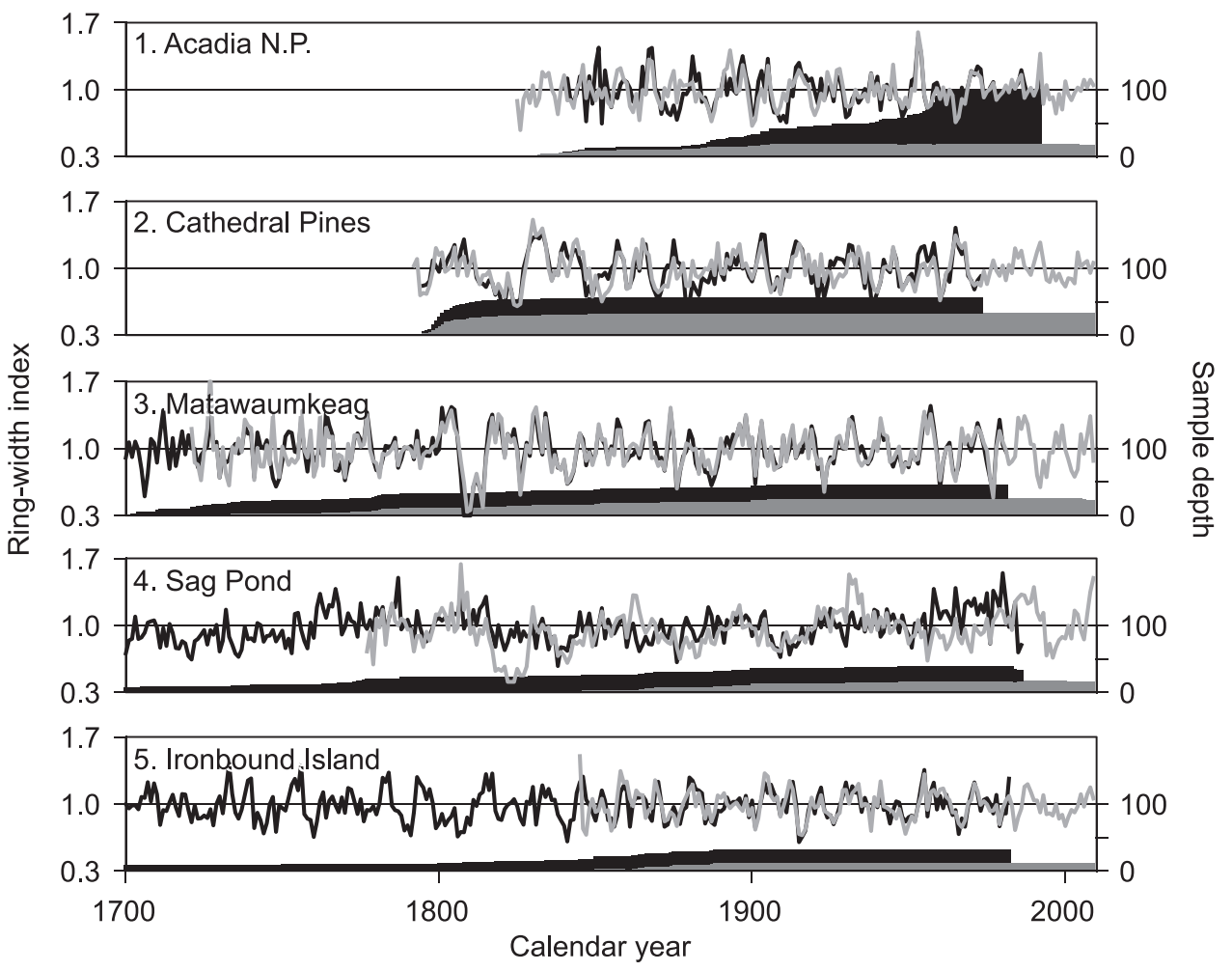

Figure 2. Ring-width index chronologies from five sites in Maine that were originally collected between 1973 and 1992 and updated with new collections through this project. Site numbers correspond to Table 1 and Figure 1.

large-scale funding, yet the importance of this task should not be underestimated. Consider the number of papers and widely-used tools that rely on data from the ITRDB. The North American Drought Atlas is derived from an extensive network of tree-ring chronologies, including those sites available through the ITRDB, and uses the period 1928-1978 for calibration (Cook et al. 1999; Cook et al. 2004). Reconstructions of broadscale climate variability often draw data from the ITRDB (e.g. Mann et al. 1998; Guiot et al. 2005; Moberg et al. 2005; Mann et al. 2008). In the case of Mann et al. (2008), all tree-ring sites were screened to cover at least the period AD 1770 1970 and have a depth of at least eight samples per year during the period $1800-1960$. There are 856 sites in the ITRDB with end dates in 1980s, meaning that even with this conservative screening a number of series included in the reconstruction could not be calibrated on the past 20-30 years of climate data. These examples are not offered to diminish the worth of these contributions, but rather to emphasize the importance of bolstering the utility of the ITRDB.

Currently there are at least 64 dendrochronology laboratories in North America alone (Henri D. Grissino-Mayer, personal communication), numerous field weeks held around the world each year, and introductory dendrochronology courses offered through a number of universities. The abundance of trained dendrochronologists around the world provides a means to update the tree-ring data available through the ITRDB. Developing new ring-width data to update existing collections provides an excellent illustration and application of the basic principles of dendrochronology and can serve the dual purposes of providing hands-on research experience for students and increasing the value of the ITRDB. Existing COFECHA outputs are available for most sites on the ITRDB and provide a valuable resource to facilitate learning the fundamentally 
important technique of crossdating among beginning dendrochronologists. We urge other faculty and instructors to conduct a search for local or regional chronologies in need of updating and accomplish this through coursework, laboratory exercises, or independent projects. Doing so will offer students opportunities to develop advanced skill sets while making real and meaningful contributions to the discipline of dendrochronology.

\section{A Sense of Urgency to Update Chronologies}

It is not surprising that we were unable to find older trees at most of the sites we sampled considering the original collections were made 30 40 years ago. However, in revisiting these sites we were struck by not only the attrition of old trees, but also the widespread mortality in some stands. On Ironbound Island we cored numerous rotten trees before our guide led us to the oldest tree sampled in the original collection. All we found was the hull of a rotten and wind-blown tree. At Matawaumkeag, the earliest inner-ring date we found was 1721, twenty-four years more recent than the earliest inner ring of the previous collection in 1982 and nearly in congruence with the passage of the years. Upon arrival at the Sag Pond site, we found the pond surrounded by recent timber harvests and exhibiting evidence of dramatic changes in water level, a new culvert, and a ring of dead northern white cedar trees (Thuja occidentalis). After numerous attempts to core rotten trees we shifted our sampling efforts to a second tier of cedar trees that, as illustrated by the chronologies, were growing in different conditions than the trees sampled in the original collection. The old trees at these sites are dying in a powerful illustration of the limits to longevity in a dynamic environment.

The need to update these chronologies soon is underscored by research suggesting trees of different ages, growing on the same sites, tend to respond differently to climate (e.g. Esper et al. 2008; Rozas et al. 2009; Copenheaver et al. 2011). These differences can be accommodated in climate reconstructions with a sufficient sample depth of trees of various ages, but if full generations are missing from a chronology the potential for temporal instability in the expressed climate response increases. In the humid and highly utilized forests of eastern North America, it is therefore reasonable to update chronologies at 30to 40-year intervals to maintain as much continuity in the chronologies as possible. This interval may be greater in arid environments, yet the additional instrumental climate data alone warrant the updating of existing chronologies.

\section{Developing Guidelines for Updating Chronologies}

Recognition of the need to update chronologies is not new within the discipline of dendrochronology and in fact is a standard practice by many researchers when time allows. A June 14, 2012, search on the ITRDB for "update", however, returned only ten chronologies. As far as we are aware there are no guidelines for updating chronologies readily available, yet such guidelines would be extremely useful for naming protocols and following statistically rigorous standards for determining what represents an update versus a new collection. Below, we offer some thoughts to begin the process of developing guidelines for this important process.

The first step to updating chronologies is selecting the sites to update. This step is influenced by time and financial constraints, but we suggest a systematic assessment of the ITRDB to prioritize geographic areas with sparse coverage of recent chronologies, sites with particularly strong climate-tree growth relationships, and sites with long chronologies. The spatial variability of climategrowth relationships must play a factor in this prioritization, as well as sites that are at risk, such as declining populations of eastern hemlock (Tsuga canadensis) caused by the invasive hemlock wooly adelgid (Hessl and Pederson, in press). Once developed, a layer that illustrates priority for updating could be added to the map interface for the ITRDB. The scope of such a project is ideal for a Master's thesis or as part of a Ph.D. dissertation and would provide an important resource for guiding the efforts of scientists new to the field of dendrochronology.

Once a site has been selected, general guidelines for the number of trees necessary to 
provide a robust update could be determined from interpretations of existing COFECHA output files, particularly the MIC (mean inter-series correlation), that can provide a simple estimate of the common signal among the targeted population. Fritts (1976), among others, suggests collecting at least two increment cores from at least 20 trees to develop a new chronology. Such broad guidelines could be modified to account for crossdating strength, forest setting, and the potential for non-climatic noise to be recorded by trees growing at that site (Cook and Kairiukstis 1990; Schweingruber 1996).

Once the samples have been processed, crossdated, and measured, the resulting ring-width data should be compared to the chronology meant to be updated. Correlation analysis, T-tests, and F-tests provide very basic metrics of similarity, but the high degrees of freedom that will commonly occur when comparing previously-collected chronologies to newly-collected chronologies may produce results that are statistically significant yet not truly robust updates. Instructions for a more elegant approach could easily be developed, such as using expressed population signal or subsample signal to determine if the newly collected data contain a similar signal to the existing data (Wigley et al. 1984) or calibration, regression analysis, and verification similar to what is commonly used in dendroclimatological studies (Fritts 1976). If these analyses show the newly developed tree-ring data to differ from the previously collected data, as is the case at Sag Pond where we report a low correlation between the previous and new collections, significantly different means based on T-tests, and significantly different variances based on F-tests, it should be considered a new collection and labeled as such (e.g. "Sag Pond new collection" from this study). If the newly developed tree-ring data are statistically similar to the previously collected data and provide a robust update, they should be submitted to the ITRDB under the original site name appended with "update" to simplify searches and aid in data management (e.g. "Cathedral Pines update" from this study). Providing detailed, quantitative guidelines for updating chronologies is beyond the scope of this report and should be determined on a site-by-site basis, but we suggest that this task, along with a detailed analysis of the ITRDB, may represent an appropriate thesis project for a graduate student, which could have wide usage and long-lasting benefits for the field of dendrochronology.

\section{ACKNOWLEDGMENTS}

Our deepest thanks go to Ray and Nancy Reitze of Earthways School of Wilderness Living and Heart Teachings of Old Turtle for capably guiding us through the North Maine Woods. Denise Cote granted permission for sampling at Cathedral Pines Campground, Peter Born encouraged sampling at Matawaumkeag Wilderness Campground, Dave Manski facilitated sampling efforts in Acadia National Park, and Richard Blaney graciously provided permission and transportation for sampling on Ironbound Island. Eric, Shelly, Danica, Mara, and Bryn Larson provided field assistance. James Markham and Colleen Smith contributed significant efforts in the preparation and analysis of tree-ring samples. Funding for this project was provided by a Scholarly Activity Improvement Fund grant from the University of Wisconsin-Platteville. This manuscript was improved through conversations with Julia Rauchfuss, Chris Underwood, and the comments of two anonymous reviewers.

\section{REFERENCES CITED}

Cook, E. R., and L. Kairiukstis, 1990. Methods of Dendrochronology: Applications in the Environmental Sciences. Kluwer Academic Publishers, Dordrecht, Netherlands, Boston; 394 pp.

Cook, E. R., and P. J. Krusic, 2005. ARSTAN v. 41d: A treering standardization program based on detrending and autoregressive time series modeling, with interactive graphics. TreeRing Laboratory, Lamont-Doherty Earth Observatory of Columbia University, Palisades, New York, USA.

Cook, E. R., D. M. Meko, D. W. Stahle, and M. K. Cleaveland, 1999. Drought reconstructions for the continental United States. Journal of Climate 12:1145-1162.

Cook, E. R., C. A. Woodhouse, C. M. Eakin, D. M. Meko, and D. W. Stahle, 2004. Long-term aridity changes in the western United States. Science 306:1015-1018.

Copenheaver, C. A., C. J. Crawford, and T. M. Fearer, 2011. Age-specific responses to climate identified in the growth of Quercus alba. Trees-Structure and Function 25:647-653. 
D'Arrigo, R., R. Wilson, B. Liepert, and P. Cherubini, 2008. On the 'Divergence Problem' in northern forests: A review of the tree-ring evidence and possible causes. Global and Planetary Change 60:289-305.

Esper, J., R. Niederer, P. Bebi, and D. Frank, 2008. Climate signal age effects - Evidence from young and old trees in the Swiss Engadin. Forest Ecology and Management 255: 3783-3789.

Fritts, H. C., 1976. Tree Rings and Climate. Academic Press, New York; 567 pp.

Grissino-Mayer, H. D., 2001. Evaluating crossdating accuracy: A manual and tutorial for the computer program COFECHA. Tree-Ring Research 57:205-221.

Grissino-Mayer, H. D., and H. C. Fritts, 1997. The International Tree-Ring Data Bank: An enhanced global database serving the global scientific community. Holocene 7:235-238.

Guiot, J., A. Nicault, C. Rathgeber, J. L. Edouard, F. Guibal, G. Pichard, and C. Till, 2005. Last-millennium summertemperature variations in western Europe based on proxy data. Holocene 15:489-500.

Hessl, A. E., and N. Pederson, in press. Hemlock legacy project (HeLP): A paleoecological requiem for eastern hemlock. Progress in Physical Geography.

Holmes, R. L., 1983. Computer-assisted quality control in treering dating and measurement. Tree-Ring Bulletin 43:69-78.

Holmes, R. L., 1999. Users Manual for Program COFECHA. Laboratory of Tree-Ring Research, Tucson, Arizona; 11 pp.

IPCC, 2007. Climate Change 2007: Synthesis Report. Intergovernmental Panel on Climate Change, Geneva, Switzerland; $52 \mathrm{pp}$.
Mann, M. E., R. S. Bradley, and M. K. Hughes, 1998. Global scale temperature patterns and climate forcing over the past six centuries. Nature 392:779-788.

Mann, M. E., Z. H. Zhang, M. K. Hughes, R. S. Bradley, S. K. Miller, S. Rutherford, and F. B. Ni, 2008. Proxy-based reconstructions of hemispheric and global surface temperature variations over the past two millennia. Proceedings of the National Academy of Sciences of the United States of America 105:13252-13257.

Moberg, A., D. M. Sonechkin, K. Holmgren, N. M. Datsenko, and W. Karlen, 2005. Highly variable Northern Hemisphere temperatures reconstructed from low- and high-resolution proxy data. Nature 433:613-617.

Orvis, K. H., and H. D. Grissino-Mayer, 2002. Standardizing the reporting of abrasive papers used to surface tree-ring samples. Tree-Ring Research 58:47-50.

Rozas, V., L. DeSoto, and J. M. Olano, 2009. Sex-specific, agedependent sensitivity of tree-ring growth to climate in the dioecious tree Juniperus thurifera. New Phytologist 182:687-697.

Schweingruber, F. H., 1996. Tree Rings and Environment Dendroecology. Swiss Federal Institute for Forest, Snow and Landscape Research, Paul Haupt, Berne; 609 pp.

Stokes, M. A., and T. L. Smiley, 1996. An Introduction to TreeRing Dating. University of Arizona Press, Tucson; 73 pp.

Wigley, T. M. L., K. R. Briffa, and P. D. Jones, 1984. On the average value of correlated time series, with applications in dendroclimatology and hydrometeorology. Journal of Climate and Applied Meteorology 23:201-213.

Received 3 March 2012; accepted 31 August 2012. 